\title{
Vismodegib and orbital excision for treating locally advanced basal cell carcinoma
}

\author{
Daniel T Hogarty' \\ Nicholas G Dewhurst' \\ Benjamin Burt ${ }^{1-4}$ \\ 'Bendigo Eye Clinic, Bendigo, VIC, \\ Australia; ${ }^{2}$ Royal Victorian Eye and Ear \\ Hospital, Melbourne, VIC, Australia; \\ ${ }^{3}$ Cosmetic Surgery for Women, \\ Melbourne, VIC, Australia; ${ }^{4}$ Canberra \\ Oculoplastics, Barton, Canberra, ACT, \\ Australia
}

This article was published in the following Dove Press journal: International Medical Case Reports Journal

\begin{abstract}
Purpose: Orbital invasion of periocular basal cell carcinoma (BCC) is a potentially lifethreatening condition with high levels of ocular morbidity. Exenteration results in significant disfigurement and permanent loss of vision. We report our experience with a patient who presented with medial orbit invasion of a $\mathrm{BCC}$ following 2 previous microscopically adequate local excisions of medial canthal BCC, an adequate Moh's micrographic surgical excision of the tumor, and radiotherapy. The patient underwent an orbital excision where the tumor was found to have perineural involvement and extend beyond the posterior margin. Following the pathology results of this procedure, the patient opted to try vismodegib (Erivedge ${ }^{\circledR}$ ) to delay exenteration for as long as possible.
\end{abstract}

Observations: A course of vismodegib was taken by the patient with minor side effects (partial alopecia, mild dysgeusia and hyposmia, and minor muscle cramps). Subsequent imaging demonstrated no recurrence of the orbital tumor 29 months after orbital excision.

Conclusion and importance: We demonstrate the use of vismodegib with local orbital excision as an eye-saving alternative to exenteration for advanced orbital metastasis of BCC.

Keywords: basal cell carcinoma, hedgehog pathway inhibitor, vismodegib, perineural, locally advanced basal cell carcinoma

\section{Introduction}

Basal cell carcinoma (BCC) that arises on the medial canthus of the eyelids is of concern. These BCCs have a higher risk of recurrence compared with carcinomas at other periocular locations. ${ }^{1}$ Recurrent $\mathrm{BCCs}$ are more aggressive and are of greater risk of invading the orbit. ${ }^{1}$ Once the orbit has been invaded, the treatment of choice is exenteration. ${ }^{2}$ Exenteration has an overall 5 -year survival rate between $55 \%$ and $65 \%$, and if there is perineural involvement, the prognosis is much worse. ${ }^{3}$

This case report discusses our experience in treating a BCC which proved to be recurrent and invasive with eventual extension into the medial orbit and evidence of significant perineural spread. Our patient was treated with local orbital excision and a sonic hedgehog inhibitor, vismodegib (Erivedge ${ }^{\circledR}$, GDC-0449; Genentech, San Francisco, CA, USA), resulting in no evidence of recurrence 29 months (17 months post-vismodegib course) after the orbital excisional surgery.

\section{Case report}

Our patient was a 51-year-old lady who was referred regarding a medial canthal BCC in December 2008. Ophthalmic examination was normal except for a lesion 
on the medial canthus of the left lower eyelid. The BCC was removed with clear margins via an excisional biopsy where the diagnosis of nodular BCC was confirmed by histopathology. Five years later, on routine follow-up, there was evidence of recurrence. Subsequently, the patient underwent another local excisional surgery which included canthoplasty, a skin muscle flap, and tarsorrhaphy. The second local excision was again reported to be clear of margins. However, considering the unexpected recurrence of the last excision, follow-up radiotherapy treatment of 46 Gy in 23 fractions using $80 \mathrm{kVp} \mathrm{X}$-rays was considered appropriate to reduce the risk of further tumor relapse. Despite this, recurrence was evident again in September 2014 in the medial canthus. Bleeding and ulceration were now significant features of the lesion and the patient was experiencing hemolacria. Therefore, the patient underwent Moh's micrographic resection where the tumor was reported as being completely removed.

In September 2015, the patient began experiencing $2 \mathrm{~mm}$ of ptosis and bleeding in the left medial canthus. A magnetic resonance imaging scan was performed, demonstrating a $10 \times 12 \mathrm{~mm}$ solid tissue mass abutting the medial bony orbital margin and medial aspect of the globe (Figure 1A). The patient underwent orbital excision to remove the left orbital tumor. Histopathology demonstrated widespread invasion of the $\mathrm{BCC}$ which went beyond the margins into the posterior orbit. The BCC was described as fibrosing/morphoeic by the pathologist with perineural involvement.

The patient, now 58 years old, expressed her wish to avoid exenteration due to the loss of sight and gross disfigurement associated with the procedure. A decision was made for the patient to attempt a new globe-sparing treatment, vismodegib.

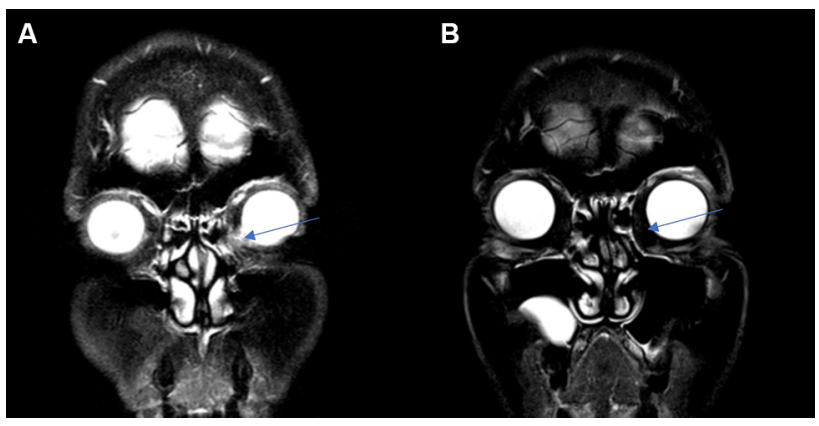

Figure I MRI before and after vismodegib and orbital excision.

Notes: Imaging of orbital BCC (A) MRI demonstrating invasive BCC of the left orbit before excision and vismodegib. (B) MRI 22 months later demonstrating no evidence of recurrence; arrow points to tumor site on both images. MRI scans taken on different machines where no exact alignment of planes could be found on pre- and postoperative scans.

Abbreviations: BCC, basal cell carcinoma; MRI, magnetic resonance imaging.
The patient was referred to the local oncology service where a 6-month course of vismodegib was prescribed after discussion with the ophthalmologist. The patient began taking $150 \mathrm{mg}$ of vismodegib daily 6 months after the orbital surgery and completed a 6-month course. At the time the drug was not on the Australian pharmaceutical benefits scheme, and so the drug company provided the drug every third month free to assist affordability for the patient.

The patient tolerated vismodegib very well. Minor muscle cramps were the first symptom experienced and were controlled with magnesium. Late in the 6-month course, the patient also experienced patches of alopecia on her scalp, and mild dysgeusia and hyposmia. The patient did not feel as though these side effects significantly impacted on her quality of life. It has now been 29 months since orbital excisional surgery and no magnetic resonance imaging (Figure 1B) and computed tomography scans since have demonstrated recurrence of the BCC. The patient has been regularly reviewed by the oculoplastic surgeon. The patient has provided written informed consent for publication of the deidentified case description and images.

\section{Discussion}

For the majority of BCCs, management with simple excision is sufficient. However, management of BCCs close to important anatomical structures such as the orbit is more complex. On some occasions of invasive spread, grossly disfiguring procedures such as exenteration and/ or ethmoidectomy may be indicated to save a patient's life. Exenteration is a challenging prospect for many patients due to predicted psychosocial challenges in addition to the surgery and recovery. ${ }^{4}$ An adjunctive/alternative therapy for locally invasive $\mathrm{BCC}$ is a hedgehog signaling pathway inhibitor called vismodegib.

Vismodegib is now on the pharmaceutical benefits scheme for metastatic or locally advanced BCC. A pivotal study in the approval of this drug for usage on BCC was the ERIVANCE study on vismodegib efficacy and safety. ${ }^{5}$ This study at 12 months found a $47.6 \%$ objective response rate, where $46.7 \%$ of those who responded had a complete response and $53.3 \%$ had a partial response at 12 months. ${ }^{5}$ Furthermore, the 12-month update of the ERIVANCE study suggested after review of images and comments from investigators that some patients assessed as having stable disease experienced substantial visible and clinically meaningful benefits from the treatment that were not captured in the primary analysis. 
This drug has been shown in a systematic review studying toxic effect profiles to not be significantly worse than other dermatologic nonbiologics and biologics. Vismodegib appears to have a similar side effect profile to the drugs used to treat advanced melanoma. ${ }^{6}$ Our patient experienced muscle cramps, alopecia, and dysgeusia, which have been reported to occur in $71.2 \%, 65.4 \%$, and $53.8 \%$ of patients taking vismodegib, respectively. ${ }^{5}$ Other common side effects associated with vismodegib usage are weight decrease, nausea, fatigue, decreased appetite, and diarrhea.

Further prospective case series have been conducted studying the efficacy of vismodegib for orbital BCC. Wong et $\mathrm{al}^{7}$ and Gill et $\mathrm{al}^{8}$ reported their experience in using vismodegib to treat 15 and 7 patients, respectively, who had periocular or orbital BCC that was not amenable to surgical resection or radiation. Gill et $\mathrm{al}^{8}$ used a short treatment course $(150 \mathrm{mg}$ daily; mean treatment duration 11 weeks; range 4-16 weeks), whereas Wong et $\mathrm{al}^{7}$ had a much longer mean treatment duration ( $150 \mathrm{mg}$ daily; mean treatment duration 13 months; range 2-40 months). Treatment duration in both studies was subject to apparent efficacy and tolerability. Wong et $\mathrm{al}^{7} \mathrm{had}$ a complete response in $67 \%$ and a partial response in $20 \%$ of patients, whereas Gill et al ${ }^{8}$ had a complete response in $29 \%$ and a partial response in $58 \%$ of patients. The drug appears to be effective in causing regression in some patients. Following our response to surgical debulking of the orbital tumor and vismodegib and the apparent efficacy of vismodegib alone, studying the techniques in combination may be useful in determining whether any additional benefit can be obtained. The patient was happy with the treatment despite experiencing side effects. She acknowledges that exenteration may be required with evidence of recurrence due to the increased risk of tumor invasion into the adjacent sinuses and cranial fossa. However, with good surgical outcomes and cosmetic appearance, the patient is satisfied with the tissue-sparing treatment.

\section{Conclusion}

Our case has demonstrated the appropriate utilization of vismodegib in conjunction with local excision to treat advanced localized BCC in the orbit, which failed in previous radiation and Moh's surgery.

\section{Author contributions}

All authors contributed toward data analysis, drafting and critically revising the paper and agree to be accountable for all aspects of the work.

\section{Acknowledgment}

The authors thank the Bendigo Eye Clinic who have facilitated this case report.

\section{Disclosure}

The authors report no conflicts of interest in this work.

\section{References}

1. Allali J, D'Hermies F, Renard G. Basal cell carcinomas of the eyelids Ophthalmologica. 2005;219(2):57-71.

2. Sun MT, Wu A, Figueira E, Huilgol S, Selva D. Management of periorbital basal cell carcinoma with orbital invasion. Future Oncol. 2015;11(22):3003-3010.

3. Tyers AG. Orbital exenteration for invasive skin tumours. Eye. 2006;20(10):1165-1170.

4. Ackuaku-Dogbe EM, Biritwum RB, Briamah ZI. Psycho-social challenges of patients following orbital exenteration. East Afr Med J. 2012;89(12):385-389.

5. Sekulic A, Migden MR, Lewis K, et al. Pivotal ERIVANCE basal cell carcinoma (BCC) study: 12-month update of efficacy and safety of vismodegib in advanced BCC. J Am Acad Dermatol. 2015;72(6):1021-1026.e8.

6. Juhasz ML, Marmur ES. Systematic review of vismodegib toxicity profile in the treatment of advanced basal cell carcinomas compared to other systemic therapies in dermatology. J Drugs Dermatol. 2014;13(6):729-733.

7. Wong KY, Fife K, Lear JT, Price RD, Durrani AJ. Vismodegib for locally advanced periocular and orbital basal cell carcinoma: a review of 15 consecutive cases. Plast Reconstr Surg Glob Open. 2017;5(7):e1424

8. Gill HS, Moscato EE, Chang AL, Soon S, Silkiss RZ. Vismodegib for periocular and orbital basal cell carcinoma. JAMA Ophthalmol. 2013;131(12):1591-1594.
International Medical Case Reports Journal

\section{Publish your work in this journal}

The International Medical Case Reports Journal is an international, peer-reviewed open-access journal publishing original case reports from all medical specialties. Previously unpublished medical posters are also accepted relating to any area of clinical or preclinical science. Submissions should not normally exceed 2,000 words or
4 published pages including figures, diagrams and references. The manuscript management system is completely online and includes a very quick and fair peer-review system, which is all easy to use. Visit $\mathrm{http}: / / \mathrm{www}$. dovepress.com/testimonials.php to read real quotes from published authors. 